\title{
Intoxicated Perpetrators of Sexual Assault \& Rape Know What They are Doing Despite Intoxication: What the Literature Has to Say
}

\author{
Scott A Johnson* \\ MA, LP, DABPS Forensic Consultation, USA
}

Submission: : January 09, 2017; Published: January 30, 2017

*Corresponding author: Scott A Johnson, MA, LP, DABPS Forensic Consultation, USA, Tel: 612-269-3628; Email: scott@forensicconsultation.org

Abstract

Far too many people claim that they did not know what they were doing when confronted about antisocial or illegal behavior they engaged in when intoxicated. Yet somehow they seem to recall most if not all pleasant or fun behavior when intoxicated. People tell their stories of how much fun they had when intoxicated, recalling most of the details of their drunken escapades. The literature suggests that people may not recall events that commonly occur and therefore some of their drunken escapades may not be recalled in full because they are routine occurrences. I postulate that events that are pleasant for an individual are likely stored in memory stronger than other events and therefore more likely to be recalled. Remember that sex related offenses and behavior an individual engages in are good or positive events for that person- they like what they are doing. Sex related offenses involve specific behavior that requires thinking (e.g., to counter victim resistance, to engage in specific sexual or other behavior on the victim, and to remove any evidence, and to escape the situation). Even with an unconscious victim, the perpetrator has to make contact without others seeing, remove any clothing, deal with any victim resistance should the victim awake, and escape without detection. I believe that sex offenders who engage in sex offenses while intoxicated have a memory of their offense and know what they are doing at the time they are doing it, despite claiming that they either

i. did not know what they were doing at the time because they were intoxicated or

ii. Have no recollection of the event because of a "black-out".

Literature suggests that even when intoxicated, individuals are aware of what they are doing and recall events via free recall and cues interviewing. In addition, though alcohol may cause cognitive and physical impairment, focusing on the desired reward of coerced or forced sex may help the perpetrator counter some of the negative impact of alcohol. Intoxicated non-rapists pay attention to peripheral cues (e.g., social sanctions against rape, peer accountability) and choose to stop sexually assaultive and rape behavior. The factors involved in the decision to sexually assault and rape are many; alcohol intoxication appears to play only a peripheral role. This is also supported by the alcohol-myopia theory. Marijuana intoxication is also briefly addressed.

Background

Alcohol does not cause anyone to become loving or violent. It is a myriad of factors that guides the judgement of the intoxicated person to make decisions on how to behave. Considering factors include the pharmacologic effect of alcohol, the environment, expectancies (self-fulfilling prophecy), as well as psychological issues (e.g., predispositions for impulsivity or antisocial traits). If alcohol intoxication "caused" a specific behavior, such as physical violence or rape, then every time the individual were intoxicated they would engage in violent or rape behavior [1]. Marijuana has also been linked with rape. One study found that marijuana is the most common used drug used for sexual assaults [2] and rape [3]. The intoxication effects of Marijuana are similar to those of other date rape drugs including Rohypnol [4]. For the victim of sexual assault or rape, intoxication makes it difficult to resist or escape the situation [5] and intoxicated or sober men's/perpetrator's tendency to misinterpret the intoxicated women's sexual intent [6]

I will refer to rape as any physically forced sexual activity. Sexual assault refers to psychologically coerced, threatened, tricked, or position of power or authority being used to take sexual contact, including having sex with an unconscious or impaired individual. Both are serious offenses, and both involve conscious decisions on the perpetrator's part. These terms may be used interchangeably throughout this article due to research methodology of numerous studies that used the terms interchangeably as well. The terms sexual offender and perpetrator may also be used interchangeably. Time and time again perpetrators of violent crime use alcohol intoxication as an excuse for reprehensible behavior [7]. Numerous studies have demonstrated that victims who voluntarily became intoxicated and perpetrators who voluntarily became intoxicated (e.g., a typical social situation involving drinking) often result in jurors holding the perpetrator less responsible for his criminal behavior and holding the victim more responsible for the rape situation because of her willingness to drink and become intoxicated [8-10]. The same results were found when the victim and/or perpetrators were intoxicated from marijuana [11,12].

The "Just World Theory" [13] demonstrates this line of attributing blame to the victim by the belief that you get what you ask for [14,15]. Heavy alcohol users are more likely to sexually assault or rape and are more likely to engage in more extreme forms of sexual assault and rape than light to moderate drinkers [16]. This may be because heavy drinking may be used by the perpetrator as an excuse to rape or because of various other issues such as personality factors (e.g., impulsivity and antisocial traits) $[17,18]$. For men who are predisposed to sexual violence, then alcohol use would more significantly increase the likelihood that these men would engage in sexual aggression [19]. Female victims who are intoxicated are often less believed and often portrayed as deserving of the rape in some way [20,21].

As a contradiction, sex offenders and offenders in general who are intoxicated at the time they commit their crime are often portrayed as being less culpable for their actions [12]. Interesting situation- blames the victim and supports the offender. Stone [22] provides an interesting legal opinion on this matter. For the sexual offender the act of coerced or forced sex is a pleasant and deliberately sought after behavior. If sexual assault and rape behavior did not offer some degree of pleasure the perpetrator would have ceased their offense behavior 


\section{Alcohol Myopia Understood}

Alcohol does not cause anyone to become loving or violent. It is a myriad of factors that guides the judgement of the intoxicated person to make decisions on how to behave. Factors for sexual assault and rape may include the pharmacologic effect of alcohol, the environment, expectancies, as well as psychological issues (e.g., predispositions for impulsivity or antisocial traits). As Steele and Joseph [1] highlight in their work, alcohol intoxication can have mixed results, ranging from aggression at one extreme to altruism at the other degree. Intoxication can also relief stress and anxiety as well as increase depression. The pharmacologic effects of alcohol are well documented and have been focused on for causing or contributing to emotions and behavior. Alcohol myopia is another factor that helps understand how alcohol intoxication impacts the individual's emotional and behavioral response.

Alcohol Myopia refers to the short-sighted information processing that result from alcohol intoxication [1]. Alcohol intoxication restricts the range of cues an individual can perceive in a situation and interferes with our ability to understand the meaning of cues we do perceive. In short, intoxication limits our experiencing and understanding of environmental cues. Intoxication does not cause an individual to act in a specific manner, but rather may help in limiting the experiencing of and interpretation of cues being given. What an intoxicated individual perceives and pays attention to tends to be the more salient, immediate cues rather than the peripheral cues. In a sober condition, an individual could pay attention to both the salient and peripheral cues and therefore make more informed decisions about how to interpret and how to react to a given situation. The more intoxicated, the more extreme the behavior tends to become. In sum, alcohol interferes with an individual's ability to attend simultaneously to multiple sets of cues, especially if the other cues are demanding incompatible behavior to the focused on or salient cues $[1,23]$.

Steel and Josephs [1] also refer to "inhibition conflict", which refers to the situation when salient and strong cues become powerful enough to ignore other cues despite others cues offering alternative problem resolution. The example the authors provide is summarized as follows. When angry with your landlord you want to fight with them and tell them off. When sober and in the situation with your landlord, your feelings and impulses to attack your landlord are strong, but you thinking about the consequences and the goal of working things out and therefore decide to be civil in your meeting. When intoxicated, your focus is on the immediate or salient factors, which is

i. experiencing negative and hostile emotions towards your landlord;

ii. being in the same room with your landlord;

iii. Wanting to harm your landlord or at least tell them off.
As a result you ignore the peripheral cues to being civil and appropriate and decide to tell your landlord off and get into it with them. In short, inhibition conflict is the ignoring of inhibiting pressures due to alcohol myopia. The authors [1] also recognize that "drunken inhibition" may occur as well.

An example of drunken inhibition is when intoxicated and being disrespected, you focus on wanting to assault the person who is provoking you. You then see the police officers arriving and approaching you and your focus is now on the officers versus the provoking party and as a result of focusing on the police, you backdown. Your salient focus is now of the officers and you have no problem with the officers and do not want to go to jail, so you back down. In summary, alcohol myopia theory [1] found that

a. alcohol can affect social behavior by blocking inhibition conflict; and

b. Drunken excessiveness in behavior may result from salient cues become the focus and peripheral cues are minimized or ignored.

The authors do not minimized the impact of self-expectancies on socially inappropriate behavior such as violent crime, but found that the role of alcohol myopia is perhaps more significant for making intoxicated decisions. Alcohol myopia restricts attention to the immediate, more salient cues in a situation and reduces processing capabilities to allow the focus to remain on the immediate, ongoing activity. "Thus, when the drinker is doing something that requires attention and thought, alcohol myopia pressures him to attend to and think about that activity over less salient worries, that is, during intoxication.

One may simply not have the processing resources to engage in a salient, ongoing activity like watching TV and to worry over one's worries at the same time" [1]. Apply this to a violent or rape situation. The perpetrator is focused on hurting or having sex with another person. That becomes the focus of the perpetrator. If the perpetrator becomes more and more intoxicated, their ability to redirect their behavior on ceasing the assault diminish greatly. But the perpetrator has to want to hurt the other person or take sex as a priority, ignoring all other thought process and moral thinking. Others have found support for the alcohol myopia theory [24]. Herrnstein [25] added that small immediate rewards are more likely to be focused on rather than delayed and uncertain negative consequences. Side note and peripherally related is how alcohol abuse/dependence may develop. Steele and Josephs [1] found that three of alcohol intoxication's social results are

a) drunken excess (alcohol's tendency to make social actions more extreme or excessive),

b) drunken self-inflation (inflated egos when viewing oneself through drunk goggles), and

c) Drunken relief (under some conditions, intoxication 
may relief psychological stress such as depression and anxiety).

\section{A reduction of intentional control when intoxicated}

Some people behave more antisocial when intoxicated. This may include engaging in risky behavior, antisocial acts, and dangerous behavior [26,27]. Some studies have demonstrated that the intentional control of intoxicated individuals tends to be demonstrated when rewards are possible [28]. When positive reinforcement is present, individuals may resist the effects of alcohol to engage in the reinforced behavior [29]. This implies that intentional control, which is often impairing when no reinforcement is present, can be overcome when rewards are available. Imagine the positive rewards for a sexual offender coercing or forcing sex is in and of itself a reinforcing activity with psychologically and physically pleasant rewards. Deliberate attention and awareness on sexual offending may help increase the perpetrator's ability to succeed in their offense behavior. Jacoby [30] found that controlled and automatic processes function jointly when the individual is working on a familiar situation or task [31]. Apply this to a sexual offender, it could be extrapolated that if the perpetrator has coerced or forced sex in the past, then this is a comfortable behavior. Thus reinforcement appears to be a powerful factor that interacts with alcohol to affect controlled processes governing intentional responses [31].

Reinforcement appears to increase controlled processes when intoxicated when a specific reward is possible. When no reward is likely, alcohol increases failures to inhibit behavior but inhibitory control is maintained when inhibitions are positively reinforced [31]. The intoxicated nonrapist, for example, considers personal and social consequences and sanctions and ceases their assaultive behavior. This appears to support that other contributing factors (e.g., personality, beliefs, expectations) impact the decision to rape while intoxicated. According to the alcohol myopia model, alcohol impacts behavior when conflicting cues simultaneously activate and inhibit behavior [1]. The intoxicated individual basically wears the beer gogglesfocusing on whatever they set out to do (e.g., having fun, rape, fighting). When conflicting stimuli occur (e.g., setting out to have fun, but someone interferes with the fun), the intoxicated individual has a difficult time shifting focus effectively to address the obstacle. The focus of having fun (the salient cues are focused on) and then someone interfering with the fun (peripheral cues), results in an overload where the intoxicated individual generally focuses only on the salient cues (having fun) and makes quick but often less effective problem solving behavior.

Numerous researchers have found that alcohol selectively interferes with specific cognitive processes that are important for inhibitory control when conflict arises [32-34]. Alcohol interferes with higher-order processing and makes it difficult to interpret complex stimuli, therefore paying attention primarily or only to salient cues [35]. The bottom line here is that the sex offender may behave more impulsively giving less regard to peripheral cues, social sanctions against forced sex, and a misinterpretation that their victims wanted the sexual contact $[1,18,36,37]$. However, this does not appear true for intoxicated nonrapists (those who do not likely present with rape supporting beliefs, personality traits related to aggression and sexual assault/rape), again supporting that a myriad of other factors appear to contribute to the decision to sexually assault or rape.

\section{Alcohol expectancies}

Alcohol expectancies involve the beliefs an individual has for how they expect alcohol consumption to impact their behavior and is based on the alcohol expectancy theory [38], which would appear to include self-fulfilling prophecies). This expectation acts to help guide the intoxicated individual to choose their behavior at the various stages of intoxication. Individuals who expect alcohol intoxication to increase their physical or sexual aggressiveness are more likely to engage in more aggressive behavior when intoxicated $[39,40]$. Sex related expectancies and sexual experiences often predicted alcohol consumption and alcohol consumption indirectly predicted sexual assault misperceptions of lack of fear of being caught [41]. Some sexual perpetrators (and nonsexual perpetrators) may believe that being intoxicated increases the assumptions or expectations that intoxication and sex go together and therefore are slower to identify their aggressive actions as being forceful or constituting rape [42].

There are varying estimations and rates of how many sexual perpetrators used alcohol prior to or during their sexual offense, ranging from $3-77 \%$, and higher for rapists versus child molesters [43-47]. Often the outcomes are more severe (rape, attempted rape, injury to victim) when the perpetrator was drinking [48]. However, extraneous factors may account for this association, such as relationship to victim, perpetrator personality factors, and victim alcohol use [49]. Testa also argues that it may be that perpetrators who are more violent may drink more on the rape day and may also be sociopathic. Research has found that the greatest injuries for a rape victim occurred with either a sober or highly intoxicated perpetrator [50].

However, the association between alcohol use and rape does not adequately explain the relationship. The role of alcohol use and sexual assault/rape situations still raises more questions than answers [49]. The pharmacological effects of alcohol on sexual aggression are difficult to separate from expectancies and personality factors [49]. The belief by the perpetrator that they have consumed alcohol may trigger expectancies which may include aggression or sexual aggression [51]. Other factors than alcohol use or intoxication appear relevant to address rape and sexual assault, such as deviance, antisocial traits, calloused sexual beliefs, sexual promiscuity, acceptance of interpersonal violence, etc. [52-54]. However, again, there is little if any 
evidence of how intoxicated the perpetrator was at the time they offended. This limitation was echoed by Testa [49].

\section{Situations and alcohol}

Sexual perpetrators do not offend on every occasion they could. Therefore situational factors must be considered. Things to consider include the relationship between perpetrator and victim , type of setting, men's misinterpretation of women's sexual intentions, self-fulfilling expectations, intoxication level of victim (making it easier to target a specific victim), the perpetrator's use of aggression (comfort with aggression, other antisocial personality traits), impact of alcohol use or intoxication on the man (perceived, pharmacologic, expectancies), victim aggressiveness, victim resistance, and victim injuries. For a full detailed discussion, see Abbey, et al. [55]. Alcohol has been linked to approximately $50 \%$ of rapes committed by juveniles and adults by numerous researchers $[6,18,56,57]$.

Several authors have merged different theories to address alcohol use and sexual aggression [35]. This integrated model suggests that men who have higher levels of alcohol use and abuse are more likely to drink to intoxication in specific settings (e.g., at the time they sexually assault or rape) and more likely to frequent places where alcohol is served. The social settings encourage the perpetrator to drink and become intoxicated (e.g., bars, parties) contributing indirectly to sexual aggression [49]. The context of the drinking location may exert independent effects on aggression independent of the pharmacologic impact. Individual differences are also important to consider, not just the role of alcohol. Situational contexts and individual characteristics impact what behavior is engaged in and whether and to what extent alcohol is used [58,59].

Extremely heavy alcohol intoxication is likely to cause cognitive, motor, and sexual impairments [55]. Therefore, the more heavily intoxicated the perpetrator becomes, the more difficulty experienced that may interfere with a successful rape. In addition, the heavily intoxicated perpetrator is more likely to engage in more deviance and aggression. This may be due to the perpetrator being increasingly frustrated of the motor and sexual deficits (erectile dysfunction, delayed/inability to ejaculate) or because of the increased alcohol myopia, expectancies, and frustration, likely a combination of many factors [60-62].

\section{Alcohol not to blame}

There is a direct association between men's attitudes about women (e.g., misogyny, use of coercion, misinterpretation of women's behavior) and sexual assault and rape in general [58]. There is no evidence that alcohol or other intoxication causes a man to rape or sexually assault anyone. The literature is full of support for the role that alcohol may play in sexual assault and rape. However, the severe limitations of the literature is that often the researchers assume one angle or one theory as explaining fully the impact of alcohol on the perpetrator's decision to sexually assault or rape. The reality is that alcohol does not, in any case, ever, cause someone to sexually assault or rape- the proof of course is that then most everyone if not everyone who was intoxicated would rape. That confounding factors are varied, and include pharmacologic impact, expectancies, situational cues, personality, and of course, contexts. The independent influences are difficult to assess and difficult to separate [55].

Alcohol intoxication has been found not to significantly impact behavior when the stimuli in the environment are simple, presented in the absence of competing demands (minimal memory load), and involve automatic processes $[63,64]$. There is support that the disinhibitory effects of alcohol on socially significant behavior (e.g., sexual and aggressive behavior) involving competing approach and avoidance contingencies [1]. Once the behavior begins, the intoxicated individual may persist in obtaining immediate gratification and experience impaired cognitive control in that peripheral cues that would normally stop the individual from continuing in coerced or forced sex, for example, are ignored [64]. The authors refer to this as "perseveration". This can also relate to problem drinkers who ignore previous negative experiences (e.g., arrests, relationship conflict, fines, treatment) resulting from or during drinking episodes and continue to drink. Alcohol appears to have the greatest impact on performance when the situation involves

i. high cognitive complexity of demands associated with working memory (causing high memory load) and

ii. The presence of prepotent (a strong, automatic inclination to select or implement one response option over another), but inappropriate response inclinations ignored [64].

The authors found that when one or both of the above conditions were absent, the impact of the alcohol on performance was minimal. In essence, the authors found that as intoxication increased, and the above two factors were present, the individual was highly likely to experience perseveration of the proponent or focused on behavior ignoring information and cues that would likely stop or interfere with the individual engaging in the specific behavior. Under heavy memory load, $80 \%$ of the intoxicated subjects continued to engage in the inappropriate behavior. Immediate gratification became the focus of the individual. Intoxication reduced working-memory processes which in turn makes it easier for the intoxicated individual to ignore cues that suggest that their focused-on behavior is wrong and to continue to obtain immediate gratification.

The pharmacological effects of alcohol on men who demonstrated hypermasculinity, those who had fewer inhibitions against sexual aggression, were the strongest in that they condoned or were less troubled by rape depictions. The opposite was found for those with low levels of hypermasculinity [65]. Other researchers [66] found that when men consumed alcohol, they were more likely to justify the depicted rapist's behavior. Alcohol has some effect in and of itself it is unclear exactly what 
the pharmacologic impact is on the perpetrator's choice to drink and commit rape or sexual assault. Pharmocologic effects, expectancies, and personality appear to all play some role in sexual assault and rape behavior $[58,59,67]$. One study found that intoxicated nonrapists were able to recognize inappropriate cues faster in an audio taped scenario than rapists and nonrapists who had not consumed alcohol [68].

Although alcohol appears to increase an individual's acceptance or interest in more deviant and violent sexual situations in the laboratory, the nonrapist group demonstrated increased vigilance and were able to more quickly identify and respond to the inappropriate cues being given and not respond with further sexual arousal. This suggests that even when intoxicated, men, or at least nonrapists, have the ability to attend to inappropriate cues and cease sexual contact. Some studies suggest that the above finding may also be related to alcohol-sex expectancies when intoxicated [69-71]. It is also important to ask whether the intoxicated man who presents with predispositions for aggression and rape, why is it that they are more unable to pay attention to inappropriate cues than intoxicated nonrapists? Perhaps the intoxicated rapist perceives the inappropriate cues (e.g., victim resistance) but either simply does not care or he may enjoy the victim's suffering and resistance. The primary differences between the intoxicated male nonrapist and rapist appear to be more related to predisposition factors, alcohol myopia (although perhaps the rapist enjoys the resistance and suffering of the victim and does in fact pay attention to the victim's resistance and suffering) as well as experiential (e.g., history of sexual abuse, witnessing parental abuse), beliefs (e.g., condoning sexual assault or rape, victim blaming), and personality factors (e.g., impulsivity, narcissism, antisocial or psychopathic).

A causal relationship between alcohol consumption and sexual assault/rape is not demonstrated given that only approximately half of the perpetrators were drinking alcohol at the time of the crime [55]. Factors and situations related to the perpetration of sexual assault and rape include (but not limited to) childhood victimization, attachment deficits, reduced capacity for empathy, witnessing parental violence, personality characteristics, narcissism, antisocial traits, disregard for social norms, tendency for aggression, early sexual experiences, promiscuity, hostility towards women, traditional views about gender roles, impulsivity, and beliefs supporting abuse and rape $[37,53,72-82]$. These factors may lead to the use and abuse of alcohol, which brings alcohol now into the mix as a contributing factor for sexual assault and rape, though alcohol use not causing the rape.

Alcohol intoxication in and of itself is not the cause of sexual assault or rape. It is unclear whether when drinking the perpetrator decides to commit the sexual assault or rape or if the perpetrator drank prior to the offense to allow an excuse or justification for the crime [55]. Knowing that alcohol plays a role for the perpetrator in justifying and committing the rape does not lessen in any way the perpetrator's responsibility for the rape behavior [83]. In the laboratory, alcohol has been shown to increase aggression. However, the effects or impact of alcohol on sexual arousal to rape are still unclear [84]. Studies have demonstrated that intoxicated subjects are more likely to use aggression and even increased aggression in the laboratory setting compared to non-intoxicated subjects. Despite this, intoxicated subjects demonstrated restrain in not initially utilizing the most severe aggression/reaction, thereby demonstrating control. This strongly indicates that intoxicated subjects are not "out-of-control" [85]. Males who were intoxicated and aggressive demonstrated sensitivity to victim and setting characteristics in that they chose different types of violence towards females versus male victims [86]. Pernanen concluded that intoxicated male still operates within socially defined limits and therefore alcohol-induced aggression is not out-of-control.

There are several factors involved in the decision to rape while intoxicated, including other factors such as alcohol myopia, expectations, beliefs, and other factors, all of which have been discussed elsewhere in this article. A Disinhibition Model links alcohol and sexual aggression $[84,85]$. They propose three factors for alcohol and rape:

i. Preexisting beliefs that alcohol serves to disinhibit, relax, etc. The strength of the disinhibition is related to amount of alcohol consumed, degree of social and personal inhibition (e.g., personality, predisposition for aggression and rape)

ii. Consuming alcohol allows for the perpetrator and others to hold the perpetrator less accountable for his actions due to the alcohol intoxication.

iii. The larger amounts of alcohol results in pharmacological effects including the inability to process inhibitory cues such as the victim's resistance.

Therefore, it is not the alcohol that causes a man to sexually assault or rape but rather a confluence of factors and a decision to sexually assault or rape. Alcohol plays a minimal peripheral role.

\section{Peer acceptance of verbal coercion and rape \& perceived certainty of punishment}

Strang and Peterson [87] found that perceived support for verbal coercion and rape may play a role in sex crimes. The support for rape culture may in fact be detrimental to treatment interventions. In fact, they found that the social factors (e.g., peer or social support for rape or coercive sex) may even impede the impact of perceptions of punishment for interpersonal violence and sex crimes. This, peer and social support may be an important factor supporting the offender's decision. Consider cases in the media [88]. 


\section{Memories of the intoxicated}

It is interesting that when criminals, especially physically and sexually violent offenders are caught, they often claim that they "did not know what they were doing" and that they "do not remember much of anything about the situation" (offense) because they were too "drunk". Two problems with this, one is that the majority of sex offenders and other violent criminals are often arrested hours if not days or months after the offense was committed. Therefore it is only the offender's word about how intoxicated they were at the time of the offense and the victim's observations. Regardless, research suggests that the majority of individuals can and do recall what they did when intoxicated when provided with cues of the situation [89]. In addition, perpetrators have little to gain to admit full knowledge of their violent and sexually abusive behavior. Another reason is that jurors may be able to relate to the perpetrator in that they may know someone who has experienced an alcohol and/ or drug problem and therefore be more sympathetic towards the perpetrators. Jurors may also blame a victim who was intoxicated at the time of the crime and hold a perpetrator who was intoxicated at the time of the crime less culpable.

It has been demonstrated that in eyewitness research, intoxicated women gave less complete, but just as accurate details compared to sober women. There were no differences found in accuracy or completeness between intoxicated or sober men- intoxicated men retaining both complete and accurate details [90]. It is important to note demonstrated differences between how men and women are impacted in regards to memory. Women demonstrate memory deficits with lower amounts of alcohol than men [90-92]. It was found that intoxicated individuals paid almost as much to peripheral and central details as sober individuals when tested a day later [93]. Numerous researchers have demonstrated that intoxicated individual were likely to attend to and recall central information versus peripheral information [94].

The amount of alcohol consumed does appear to impact the quantity of information from memory. However, the overall accuracy of the information was equally accurate between intoxicated and sober individuals [95-97]. Sober individuals were found to be more likely to be aware of, monitor, and control memory reporting and therefore more likely to report "I don't know" that intoxicated individuals [94]. This implies that intoxicated individuals had a decreased capacity to regulate their memory reports. One study [95] found that regardless of intoxication, that participants remembered more central than peripheral details, which differs from other results that intoxicated individuals tend to not remember peripheral details. That research involved s stronger emotional event which may have helped strengthen the individual's recall of central and peripheral detail. Sexual assault and rape arguably are a much stronger emotional event for both the victim (a negative experience) and for the perpetrator (a positive emotional event).

\section{Witness interviewing}

When interviewing witnesses it is important to understand the impact of alcohol intoxication. At high levels (0.07-0.1\%) impairment in completeness in witness statements under free recall situations was demonstrated $[90,96,97]$. Other studies found high accuracy rates in intoxicated witnesses under similar alcohol impairment, but only under free recall situations versus structured interview formats [94]. Immediate interview of eyewitnesses provided the most accurate completeness though again the quantity of information is reduced due to the impact of the alcohol intoxication on memory [96].

Immediate interviewing of witnesses is important. In fact, immediate interviewing resulted in more correct details than when interviewing a witness only at a later time [98]. This was true for both intoxicated and sober witnesses. They also found that interviewing on two occasions resulted in more correct details than only interviewing a witness once, regardless of whether intoxicated or sober. As indicated in the previous section, intoxicated witnesses recalled fewer details than sober witnesses in free recall, but provided the same amount of information as sober witnesses in cued recall [98]. Several studies found that low to moderate intoxication (e.g., up to 08$10 \%)$ did not interfere with the quantity of details the witness provided [90,98-100]. At higher doses, alcohol intoxication appeared to impair both the quantity and quality of witness statements, though to a small degree [97]. Evidence supports that immediately interviewing a witness who is moderately intoxicated (up to approximately .10\%) is better than only a oneweek delayed interview. In addition, both sober and intoxicated witnesses provided 20-30\% more details during a second interview than had they only been interviewed once [98].

Approximately $80 \%$ of reminiscent details (later recalls) provided by sober or intoxicated witnesses were correct [98]. This is furthered strengthened when no misleading questions were asked by interviewers. The authors also found that alcohol reduced the number of recalled details in free recall but not in cued recall. They also found that both sober and intoxicated witnesses were more accurate in free recall versus cued recall. It is important to begin with free recall and allow the witness to finish telling what they recall before moving into direct questioning. The reason for this is that direct questioning can have a contaminating effect on witness memory $[98,101]$. In sum: if low to moderate intoxication, witnesses recalled significant details then it stand to reason that the perpetrator would also recall their offense behavior. Again with the caveat that most sex offenders are not caught within a couple of hours following the offense and therefore there is no way to know how intoxicated the perpetrator was at the time of their offense. Self-report is biased and the perpetrator has more to gain to claim that they were too intoxicated to know what they were doing (which is never the case). It is also difficult to know if the perpetrators used alcohol at all before or during the sexual assault or rape 
again because the perpetrator is most often arrested at a later time.

\section{Legal implications}

When a perpetrator was intoxicated with marijuana at the time of his crime, it is often assumed that because he was "high" and impaired, that he is somehow not responsible for his actions. This is not support by any of the literature [12]. Jurors may be biased in favor of assigning less responsibility for the crime to the perpetrator when the perpetrator was intoxicated or under the influence of marijuana. Temkin [102] recommends informing jurors that extra-legal issues (e.g., alcohol and drug intoxication) should not impact issue of criminal responsibility [102]. The intoxicated perpetrator of sexual assault or rape made a conscious decision to engage in the assault/rape, despite being intoxicated. A myriad of other factors played a role in the perpetrator's decision to sexually assault or rape, alcohol playing only a minimal peripheral role. Again, intoxicated nonrapists ceased their assaultive behavior whereas intoxicated sexual assaulters and rapists did not. As for memory recall of the sexual assault or rape, evidence previously discussed suggests that the perpetrator should be able to recall the offense details under free recall and cued recall situations. See Johnson [89] for more on the role of alcohol in rapes.

\section{Personality}

Personality factors have been correlated to violence in general, including sex crimes. For those with personality traits including, but not limited to narcissism, antisocial, and other traits may simply not be concerned with taking the risks involved in violent crime. In addition, such individuals may give little if any regard to the consequences or punishments for their behavior $[87,103]$. The personality factors related to sexual assault and rape have been previously discussed. Personality and other factors include, but are not limited to, childhood victimization, attachment deficits, reduced capacity for empathy, witnessing parental violence, personality characteristics, narcissism, antisocial traits, disregard for social norms, tendency for aggression, early sexual experiences, promiscuity, hostility towards women, traditional views about gender roles, impulsivity, and beliefs supporting abuse and rape.

\section{Why perpetrators sexually assault or rape}

There is a plethora of literature addressing why sexual assault and rape occur. Most of the research identifies several factors leading to the decision to engage in a sex offense. These factors can include personality traits, attitudes (e.g., condoning sexual assault/rape, victim blaming), substance use/abuse, and psychopathy [55]. The reasons have been previously discussed and come down to the perpetrator making a conscious decision to sexually assault or rape.

\section{Summary}

One serious limitation of most of the studies cited in this article is that sexual offenders often claim that they were "too drunk to know what they were doing" of that they "did not know what they were doing because they were too intoxicated". Again, because the majority of sexual offenders are not arrested until hours, days and even months following the crime, it is impossible to know how intoxicated they were at the time of the offense. It is also impossible to know what their true motivations were for the offense. Groth [104] (p.2 and through-out the book) and many others wrote that sexual satisfaction was only one, but not the primary motivation for a sex crime. It is important to separate research results that utilize laboratory settings, controlling for various factors, yet are not in fact real-life situations occurring at that moment. There is no proof offered in any of the research that a sexual offender is "out-of-control" or not aware of what they are doing. Sexual assault and rape involve coercion and/or physical force. The offender has to obtain their victim, conduct the sexual assault or rape, and then go about their lives as though nothing has happened.

Most try to avoid leaving evidence and many believe that their victim asked for or deserved in their (perpetrator) mind, the sexual experience or forced sexual experience. Even for those sex crimes involving an unconscious victim, the perpetrator had to justify having sex with an unconscious person, and often removes evidence or attempts to redress the victim, implying that they were aware that their actions (sexual assault or rape) were not sanctioned or acceptable. One shortcoming of some of the research is that it is assumed that the intoxicated individual is accurately reporting what they are experiencing and thinking. In addition, it is not how intoxication the perpetrator was at the time of the offense, and the self-reported intoxication and inability to recall offense details has self-serving benefits. The research provides a lot of information about the factors involved in sexual assault and rape and the role of alcohol. The overall conclusions suggest that the perpetrator made conscious decisions about their offense behavior.

\section{References}

1. Steele CM, Josephs RA (1990) Alcohol myopia: Its prized and dangerous effects. Am Psychol 45(8): 921-933.

2. Scott-Ham M, Burton FC (2005) Toxicological findings in cases of alleged drug-facilitated sexual assault in the United Kingdom over a 3-year period. J Clin Forensic Med 12(4): 175-186.

3. McCauley JL, Ruggiero KJ, Resnick HS, Kilpatrick DG (2010) Incapacitated, forcible, and drug/alcohol facilitated rape in relation to binge drinking, marijuana use, and illicit drug use: A national survey. J Trauma Stress 23(1): 132-140.

4. L Slaughter (2000) Involvement of drugs in sexual assault. Journal of Reproductive Medicine 45(5): 425-430.

5. Abbey A, Clinton Sherrod AM, McAuslan P, Zawacki T, Buck PO (2003) The relationship between the quantity of alcohol consumed and the severity of sexual assaults committed by college men. J Interpers Violence 18(7): 813-833.

6. Antonia Abbey, Pam McAuslan, Lisa Thomson Ross (1998) Sexual assault perpetration by college men: The role of alcohol, misperception of sexual intent, and sexual beliefs and experiences. Journal of Social and Clinical Psychology 17(2): 167-195. 
7. Critchlow B (1986) The powers of John Barleycorn: Beliefs about the effects of alcohol on social behavior. Am Psychol 41(7): 751-764.

8. Clare Carlson (2014) "This bitch got drunk and did this to herself." proposed evidentiary reforms to limit "victim blaming" and "perpetrator pardoning" in rape by intoxication trials in California. Wisconsin Journal of Law, Gender \& Society 29(2): 285-315.

9. Emily Finch, Vanessa E Munro (2007) The demon drink and the demonized woman: socio-sexual stereotypes and responsibility attribution in rape trials involving intoxicants. Social \& Legal Studies 16(4): 591-614.

10. Girard AL, Senn CY (2008) The role of the new 'date rape drugs' in attributions about date rape. J Interpers Violence 23(1): 3-20.

11. Charmaine A Cameron, Werner GK Stritzke (2003) Alcohol and acquaintance rape in Australia: Testing the presupposition model of attributions about responsibility and blame. Journal of Applied Social Psychology 33(5): 983-1008.

12. Sandie J Qi, Louise C Starfelt, Katherine M White (2016) Attributions of responsibility, blame and justifiability to a perpetrator and victim in an acquaintance rape scenario: the influence of Marijuana intoxication. Journal of Sexual Aggression 22(1): 20-35.

13. Lerner Melvin (1980) The Belief in a Just World: A Fundamental Question. Plenum, USA.

14. Irina Anderson, Geoffrey Beattie, Christopher Spencer (2001) Can Blaming Victims of Rape be Rational? Attribution Theory and Discourse Analytic Perspectives. Human Relations 54(4): 445-467.

15. Linda A Foley, Melissa A Pigott (2000) Belief in a Just World and Jury Decisions in a Civil Rape Trial. Journal of Applied Social Psychology 30(5): 935-951.

16. Sarah E Ullman, George Karabatsos, Mary P Koss (1999) Alcohol and sexual aggression in a national sample of college men. Psychology of Women Quarterly 23(4): 673-689.

17. Abbey A, McAuslan P, Zawacki T, Clinton AM, Buck PO (2001) Attitudinal, experiential, and situational predictors of sexual assault perpetration. J Interpers Violence 16(8): 784-807.

18. Diana Scully (1991) Understanding sexual violence: a study of convicted rapists. Unwin Hyman, USA.

19. Hall GC (1989) Sexual arousal and arousability in a sexual offender population. J Abnorm Psychol 98(2): 145-149.

20. Lisa A Harrison, Dawn M Howerton, Ashley M Secarea, Chau Q Nguyen (2008) Effects of ingroup bias and gender role violations on acquaintance rape attributions. Sex Roles 59(9): 713-725.

21. Ashley A Wenger, Brian H Bornstein (2006) The effects of victim substance use and relationship closeness on mock jurors judgments in an acquaintance rape case. Sex Roles 54(7): 547-555.

22. Stone J (2013) Rape, Consent and Intoxication: A Legal Practitioner's Perspective. Alcohol Alcohol 48(4): 384-385.

23. Jeffrey A Gray (1978) The neuropsychology of anxiety. British Journal of Psychology 69(4): 417-434.

24. James D Johnson, Nora E Noel, Janice Sutter-Hernandez (2000) Alcohol and male acceptance of sexual aggression: the role of perceptual ambiguity. Journal of Applied Social Psychology 30(6): 1186-1200.

25. Richard J Herrnstein (1990) Rational choice theory: Necessary but not sufficient. American Psychologist 45(3): 356-367.

26. Bushman BJ (1997) Effects of alcohol on human aggression: validity of proposed explanations. Recent Dev Alcohol 13: 227-243.

27. Steele CM, Southwick L (1985) Alcohol and social behavior I: The psychology of drunken excess. J Pers Soc Psychol 48(1): 18-34.
28. Murial Vogel Sprott (1992) Alcohol Tolerance and Social Drinking: Learning the Consequences. The Guillford Press, USA.

29. Murial Vogel Sprott, Mark T Fillmore (1999) Learning theory and research in Psychological Theories of Drinking and Alcoholism ( $2^{\text {nd }}$ edn). In: Howard T Blane \& Kenneth E Leonard (Eds.), Guilford Press, USA, pp. 292-327.

30. Jacoby Larry L, Toth Jeffrey P, Yonelinas Andrew P (1993) Separating conscious and unconscious influences of memory: Measuring recollection. Journal of Experimental Psychology: General 122(2): 139-154.

31. Grattan KE, Vogel Sprott M (2001) Maintaining Intentional Control of Behavior Under Alcohol. Alcohol Clin Exp Res 25(2): 192-197.

32. Fillmore MT, Vogel Sprott M (1999) An alcohol model of impaired inhibitory control and its treatment in humans. Exp Clin Psychopharmacol 7(1): 49-55.

33. Fillmore MT, Vogel Sprott M (2000) Response inhibition under alcohol: Effects of cognitive and motivational conflict. J Stud Alcohol 61(2): 239-246.

34. Gordon D Logan, William B Cowan (1984) On the ability to inhibit thought and action: A theory of an act of control. Psychological Review 91(3): 295-327.

35. Chermack ST, Giancola PR (1997) The relation between alcohol and aggression: an integrated biopsychosocial conceptualization. Clin Psychol Rev 17(6): 621-649.

36. Taylor SP, Leonard KE (1983) Alcohol and human physical aggression. In RG Geen \& EI Donnerstein (Eds.), Aggression: theoretical and empirical reviews, Academic Press, USA, Volume 2: p. 77-101.

37. Tony Warda, Thomas Keenana, Stephen M Hudson (2000) Understanding cognitive, affective, and intimacy deficits in sexual offenders: a developmental perspective. Aggression and Violent Behavior 5(1): 41-62.

38. Craig MacAndrew, Robert B Edgerton (1969) Drunken comportment: A social explanation. Aldine, USA

39. Antonia Abbey, Pam Mcauslan, Lisa Thomson Ross, Tina Zawacki (1999) Alcohol expectancies regarding sex, aggression, and sexual vulnerability: Reliability and validity assessment. Psychology of Addictive Behaviors 13(3): 174-182.

40. Dermen Kurt H, Cooper M Lynne (1994) Sex-related alcohol expectancies among adolescents: II Prediction of drinking in social and sexual situations. Psychology of Addictive Behaviors 8(3): 161-168.

41. Antonia Abbey, Lisa Thomson Ross, Donna McDuffie, Pam McAuslan (1996) Alcohol and dating risk factors for sexual assault among college women. Psychology of Women Quarterly 20(1): 147-169.

42. Jeffrey A Bernat, Karen S Calhoun, Stephanie Stolp (1998) Sexually aggressive men's responses to a date rape analogue: alcohol as a disinhibiting cue. Journal of Sex Research 35(4): 341-348.

43. Brecklin LR, Ullman SE (2002) The roles of victim and offender alcohol use in sexual assaults: results from the National Violence Against Women Survey. J Stud Alcohol 63(1): 57-63.

44. Gudjonsson GH, Sigurdsson JF (2000) Differences and similarities between violent offenders and sex offenders. Child Abuse Negl 24(3): 363-372.

45. Lightfoot LO, Barbaree HE (1993) The relationship between substance use and abuse and sexual offending in adolescents. In: HE Barbaree, et al. (Eds.), The juvenile sex offender, Guilford, USA, pp. 203-224.

46. Roizen J (1997) Epidemiological issues in alcohol-related violence. In: M Galanter (Eds.), Recent developments in alcoholism, Plenum, USA, p. 7-40. 


\section{Journal of Forensic Sciences \& Criminal Investigation}

47. Ullman SE (1999) A comparison of gang and individual rape incidents. Violence Vict 14(2): 123-133.

48. Bushman BJ, Cooper HM (1990) Effects of alcohol on human aggression: An integrative research review. Psychol Bull 107(3): 341-354.

49. Maria Testa (2002) The impact of men's alcohol consumption on perpetration of sexual aggression. Clinical Psychology Review 22(8): $1239-1263$

50. Abbey A, Clinton AM, McAuslan P, Zawacki T, Buck PO (2002) Alcoholinvolved rapes: are they more violent? Psychol Women Q 26(2): 99109.

51. Goldman MS, DelBoca FK, Darkes J (1999) Alcohol expectancy theory: an application of cognitive neuroscience $\left(2^{\text {nd }} e d n\right)$. In: KE Leonard \& HT Blane (Eds.), Psychological theories of drinking and alcoholism, Guilford, USA, pp. 203-246.

52. Jeffrey A Bernat, Stephanie Stolp, Karen S Calhoun, Henry E Adams (1997) Construct validity and test-retest reliability of a date rape decision-latency measure. Journal of Psychopathology and Behavioral Assessment 19(4): 315-330.

53. Koss MP, Gaines JA (1993) The prediction of sexual aggression by alcohol use, athletic participation, and fraternity affiliation. Journal of Interpersonal Violence 8(1): 94-108.

54. Marx Brain P, Gross Alan M (1995) Date rape: an analysis of two contextual variables. Behavior Modification 19(4): 451-463.

55. Abbey A, Zawacki T, Buck PO, Clinton AM, McAuslan P (2004) Sexual assault and alcohol consumption: what do we know about their relationship and what types of research are still needed? Aggress Violent Behav 9(3): 271-303.

56. Ageton SS (1983) Sexual assault among adolescents. Lexington Books, USA.

57. Collins JJ, Messerschmidt PM (1993) Epidemiology of alcohol-related violence. Alcohol Health and Research World 17: 93-100.

58. Malamuth NM, Sockloskie RJ, Koss MP, Tanaka JS (1991) Characteristics of aggressors against women: Testing a model using a national sample of college students. J Consult Clin Psychol 59(5): 670-681.

59. Zawacki T, Buck P, Abbey A, McAuslan P, Clinton AM (2001) Predicting alcohol use during sexual assault: differences in perpetrators personality, attitudes, and experiences. Research Society on Alcoholism, Canada.

60. GM Farkas, RC Rosen (1976) Effect of alcohol on elicited male sexual response. Journal of Studies on Alcohol and drugs 37(3): 265-272.

61. Victor J Malatesta, Robert H Pollack, WA Wilbanks, Henry E Adams (1979) Alcohol effects on the orgasmic-ejaculatory response in human males. Journal of Sex Research 15(2): 101-107.

62. Pihl RO, Peterson JB, Lau MA (1993) A biosocial model of the alcoholaggression relationship. J Stud Alcohol Suppl 11: 128-139.

63. Davis KC, Kiekel PA, Schraufnagel TJ, Norris J, George WH (2012) Men's alcohol intoxication and condom use during sexual assault perpetration. J Interper Violence 14(14): 2790-2806.

64. Casbon TS, Curtin JJ, Lang AR, Patrick CJ (2003) Deleterious Effects of Alcohol Intoxication: Diminished Cognitive Control and Its Behavioral Consequences. J Abnorm Psychol 112(3): 476-487.

65. Donald L Mosher, Mark Sirkin (1984) Measuring a macho personality constellation. Journal of Research in Personality 18(2): 150-163.

66. Norris J, Martell J, George WH (2001) Men's judgments of a sexual assailant in an eroticized rape: the role of rape myth attitudes and contextual factors. In: M Martinez (Eds.), Prevention and control of aggression and the impact on its victims, Kluwer Academic Publishers/ Plenum, USA, pp. 249-254.
67. Payne Diana L, Lonsway Kimberly A, Fitzgerald Louise F (1999) Rape myth acceptance: Exploration of its structure and its measurement using the Illinois Rape Myth Acceptance Scale. Journal of Research in Personality 33(1): 27-68.

68. Wydra A, Marshall WL, Earls CM, Barbaree HE (1983) Identification of cues and control of sexual arousal by rapists. Behavior Research and Therapy 21(5): 469-476.

69. WH George, KH Dermen, TH Nochajski (1989) Expectancy set, selfreported expectancies and predispositional traits: Predicting interest in violence and erotica. J Stud Alcohol 50(6): 541-551.

70.William H George, G Alan Marlatt (1986) The effects of alcohol and anger on interest in violence, erotica, and deviance. Journal of Abnormal Psychology 95(2): 150-158.

71. Mary Mcmurran, Helen Bellfield (1993) Sex-related alcohol expectancies in rapists. Criminal Behaviour and Mental Health 3(2): 76-84

72. Barbaree HE, Marshall WL (1991) The role of male sexual arousal in rape: six models. J Consult Clin Psychol 59(5): 621-630.

73. HE Barbaree, WL Marshall, J McCormick (1998) The development of deviant sexual behaviour among adolescents and its implications for prevention and treatment. Irish Journal of Psychology 19(1): 1- 31.

74. Dean KE, Malamuth NM (1997) Characteristics of men who aggress sexually and of men who imagine aggressing: risk and moderating variables. J Pers Soc Psychol 72(2): 449-455

75. David S Kosson, Jennifer C Kelly, Jacquelyn W White (1997) Psychopathy-related traits predict self-reported sexual aggression among college men. Journal of Interpersonal Violence 12(2): 241-254

76. Martin L Lalumière, Lori J Chalmers, Vernon L Quinsey, Michael C Seto (1996) A Test of the Mate Deprivation Hypothesis of Sexual Coercion. Ethology and Sociobiology 17(5): 299-318.

77. Lisak D, Roth S (1988) Motivational factors in nonincarcerated sexually aggressive men. J Pers Soc Psychol 55(5): 795-802.

78. Malamuth NM, Linz D, Heavey CL, Barnes G, Acker M (1995) Using the confluence model of sexual aggression to predict men's conflict with women: a 10-year follow-up study. J Pers Soc Psychol 69(2): 353-369.

79. Malamuth NM, Heavey CL, Linz D (1993) Predicting men's antisocial behavior against women: The interaction model of sexual aggression. In: GCN Hall, et al. (Eds.), Sexual aggression: Issues in etiology, assessment and treatment, Taylor \& Francis, USA, p. 63-97.

80. Prentky RA, Knight RA (1991) Identifying critical dimensions for discriminating among rapists. J Consult Clin Psychol 59(5): 643-661.

81. Charlene Y Senn, Serge Desmarais, Norine Verberg, Eileen Wood (2000) Predicting coercive sexual behavior across the lifespan in a random sample of Canadian men. Journal of Social and Personal Relationships 17(1): 95-113.

82. Seto MC, Barbaree HE (1997) Sexual aggression as antisocial behavior: a developmental model. In: DM Stoff, et al. (Eds.), Handbook of antisocial behavior, Wiley, USA, pp. 524-533.

83. Shaver KG (1987) The attribution of blame. Springer-Verlag, USA.

84. Michael C Seto, Howard E Barbaree (1995) The role of alcohol in sexual aggression. Clinical Psychology Review 15(6): 545-566.

85. Taylor SP, Chermack ST (1993) Alcohol, drugs and human physical aggression. J Stud Alcohol Suppl 11: 78-88.

86. Pernanen K (1991) Alcohol and human violence. Guildford Press, USA.

87. Strang E, Peterson ZD (2013) The Relationships Among Perceived Peer Acceptance of Sexual Aggression, Punishment Certainty, and Sexually Aggressive Behavior. J Interpers Violence 28(18): 3369-3385. 
88. Johnson, S.A., (2017) Societal Acceptance of Crime \& Rape: Blaming Victims and Excusing the behavior of the Offender. Journal of Forensic Sciences \& Criminal Investigation 1(3): 1-5.

89. Johnson SA (2014) Understanding the Role of Alcohol During Rape: The Perfect Storm of Attention, Emotion \& Expectancies. Int J Emerg Ment Health 16(1): 259-269.

90. Malin Hildebrand Karlén, Emma Roos af Hjelmsäter, Claudia Fahlke, Pär Anders Granhag, Anna Söderpalm Gordh (2015) Alcohol intoxicated eyewitnesses' memory of intimate partner violence. Psychology, Crime \& Law 21(2): 156-171.

91. Bergman H, Källmén H (2002) Alcohol use among Swedes and a psychometric evaluation of the Alcohol Use Disorders Identification Test. Alcohol Alcohol 37(3): 245-251.

92. Mumenthaler MS, Taylor JL, O Hara R, Yesavage JA (1999) Gender differences in moderate drinking effects. Alcohol Res Health 23(1): 55-64.

93. Harvey AJ, Kneller W, Campbell AC (2013) The effects of alcohol intoxication on attention and memory for visual scenes. Memory 21(8): 969-980

94. Compo NS, Evans JR, Carol RN, Kemp D, Villalba D, et al. (2011) Alcohol intoxication and memory for events: A snapshot of alcohol myopia in a real-world drinking scenario. Memory 19(2): 202-210.

95. Flowe HD, Takarangi MK, Humphries JE, Wright DS (2016) Alcohol and remembering a hypothetical sexual assault: Can people who were under the influence of alcohol during the event provide accurate testimony? Memory 24(8): 1042-1061.

96. Kim van Oorsouw, Harald Merckelbach (2012) The effects of alcohol on crime-related memories: A field study intoxication and memory for crime. Applied Cognitive Psychology 26(1): 82-90.

97. Yuille JC, Tollestrup PA (1990) Some effects of alcohol on eyewitness memory. J Appl Psychol 75(3): 268-273.

98. Angelica V Hagsand, Emma Roos Af Hjelmsäter, Pär Anders Granhag, Claudia Fahlke, Anna Söderpalm Gordh (2016) Witnesses stumbling down memory lane: The effects of alcohol intoxication, retention interval and repeated interviewing. Memory: 1-13.

99. Deborah Crossland, Wendy Kneller, Rachel Wilcock (2016) Intoxicated witnesses: Testing the validity of the alcohol myopia theory. Applied Cognitive Psychology 30(1): 270-281.

100. Compo NS, Evans JR, Carol RN, Villalba D, Ham LS, et al. (2012) Intoxicated eyewitnesses: Better than their reputation? Law Hum Behav 36(2): 77-86.

101. Koriat A, Goldsmith M (1996) Monitoring and control processes in the strategic regulation of memory accuracy. Psychol Rev 103(3): 490-517.

102. Jennifer Temkin (2010) "And always keep a-hold of nurse, for fear of finding something worse": Challenging rape myths in the courtroom. New Criminal Law Review 13(4): 710-734.

103. Zawacki T, Abbey A, Buck PO, McAuslan P, Clinton-Sherrod AM (2003) Perpetrators of alcohol-involved sexual assault: How do they differ from other sexual assault perpetrators and nonperpetrators. Aggress Behav 29(4): 366-380.

104. Groth AN (1990) Men who rape: The psychology of the offender. Plenum Press, USA.

\section{Your next submission with Juniper Publishers will reach you the below assets}

- Quality Editorial service

- Swift Peer Review

- Reprints availability

- E-prints Service

- Manuscript Podcast for convenient understanding

- Global attainment for your research

- Manuscript accessibility in different formats

( Pdf, E-pub, Full Text, Audio)

- Unceasing customer service

Track the below URL for one-step submission https://juniperpublishers.com/online-submission.php 